\title{
Within and Cross Volatility Contagion Effects among Stock, Crude and Forex Returns: Empirical Evidence from Five Emerging Economies
}

\author{
George Varghese \\ Institute for Financial Management and Research (IFMR), Central Expressway, Sector 24, Sri City, Satyavedu, India \\ Email: george.v@ifmr.ac.in
}

How to cite this paper: Varghese, G. (2018) Within and Cross Volatility Contagion Effects among Stock, Crude and Forex Returns: Empirical Evidence from Five Emerging Economies. Theoretical Economics Letters, 8, 1475-1492.

https://doi.org/10.4236/tel.2018.88095

Received: April 12, 2018

Accepted: June 4, 2018

Published: June 7, 2018

Copyright $\odot 2018$ by author and Scientific Research Publishing Inc. This work is licensed under the Creative Commons Attribution International License (CC BY 4.0).

http://creativecommons.org/licenses/by/4.0/

\begin{abstract}
The paper examines the spillover effects of return volatility among stock market index, foreign exchange market and WTI crude oil market across five emerging nations. Here a Trivariate Diagonal BEKK-GARCH model is used to estimate the time-varying conditional variance and to test the own-volatility spillover effects of returns among the three underlying variables. We find that significant own volatility spillover exists in the WTI returns followed by that of stock returns and forex returns. Further, fluctuations in WTI returns exert considerable influence over the stock market volatilities. The lagged variance of the variables as well as their lagged squared residuals from the mean equation has a positive and significant impact on the current volatility in most cases. The findings of the study are of pertinent importance to financiers, economists, investors and policymakers.
\end{abstract}

\section{Keywords}

Stock Market, Foreign Exchange, Crude Oil, BEKK GARCH, Clustering, Volatility Spillover

\section{Introduction}

A flourishing stock market attracts capital inflows from foreign investors leading to an increase in the demand for a country's domestic currency. The converse would happen in case of decreasing stock prices where the shareholders/investors try to sell off their stocks so as to evade further loss. As a result, upward and downward movement of stock prices would reflect itself through 
appreciation and depreciation in foreign exchange rates. However, appreciation in the domestic currency inversely affects the national stock market for an export dominant country while it positively affects the national stock market for an import dominant country.

Oil import/export constitutes a significant portion of the demand/supply for dollar in a country's foreign exchange market. This contributes to the appreciation or depreciation of domestic currencies against US dollar. Moreover, exchange rates and oil prices are anticipated to have a positive and statistically significant impact on stock markets. However, some studies have also shown oil price changes to have no significant influence over stock market returns [1] [2].

Understanding the influence of oil price changes/shocks on the financial as well as foreign exchange markets, particularly in the case of emerging economies would be of paramount importance as these economies are inclined to exert a greater influence over the global economy in the forthcoming years. Additionally, with the liberalization of the capital accounts and the integration of capital markets, investors' world over would be anticipated to diversify their portfolios across international currencies as well as national stock markets. Further, the association between oil price fluctuations and the corresponding movements in the stock markets and foreign exchange rates has attracted the attention of investors and researchers alike over the past few decades, as crude oil prices exhibit exceptional volatility, leading to an increasing uncertainty in the whole economy and particularly in the financial and foreign exchange markets.

If the price returns and their volatilities thereof of these three variables, namely, WTI crude oil returns, corresponding stock market as well as forex returns are dynamically interrelated, then a random shock in the price return of any one of these variables will soon get reflected in the price returns and the return volatility of the other two variables as a result of an underlying relationship called as "spillover effect". In most cases, the fluctuations in the prices of these macroeconomic variables are determined by the domestic as well as the global market forces leading to randomness in the underlying returns. This randomness in returns is popularly understood through the returns volatility which is otherwise known as returns with heteroscedastic variance. This volatility induced through a random shock may then persist over a longer period of time resulting in volatility clustering; a phenomenon wherein, a period of high returns is consequently followed by subsequent periods of higher returns and a period of low returns is consequently followed by subsequent periods of lower returns. With increasing global integration and unrestricted flow of capital across borders, shocks in financial markets tend to spread across other financial markets within and across national boundaries.

Since randomness is a natural outcome for a financial time series data, volatility of such series does not remain constant over time. Modeling this heteroscedastic variance required theories on dynamic volatility and this gap was duly filled by the ARCH (Autoregressive Conditional Heteroscedasticity) family of 
models. Subsequently, the ARCH/GARCH models were extensively used in volatility spillover studies. In our study, we try to analyze the own as well as cross volatility contagion effects across stock returns, crude oil returns and forex returns for five emerging economies, namely, Brazil, Indonesia, Malaysia, Pakistan and South Korea. We use the Diagonal BEKK GARCH model to assess the volatility contagion effects between the three underlying markets.

The economies that possess some characteristics of a developed market yet do not meet all the standards of a developed economy are called emerging economies. Such economies invest more on productive capacity and by way of which achieve rapid growth. With an ongoing strive to become more and more advanced, investments in emerging economies comes with higher return potential. Nevertheless, these economies also assume much higher risk because of the high volatilities in their financial markets.

The remaining part of the paper is organized as follows. Section two briefly discusses the literature existing in the area of study and highlights the gap which the present study attempts to fill. Section 3 describes the data that is employed in the study which is then followed by a subsequent section that gives a concise description of the econometric models used in meeting the study objectives. Section 5 gives the detailed analysis of the empirical exercise and Section 6 concludes the paper.

\section{Literature Review}

Wang M.L. et al. [3] in his paper, studied the impact of fluctuations in US dollar value against other countries on the stock prices using a high frequency, daily time series data. The study covered the exchange rates and stock markets of the United States, Germany, Japan, China and Taiwan. They explored the short term as well as long-term correlations between exchange rates and the stock market and found them to be strongly cointegrated in the case of Japan, China, Germany, and Taiwan. Sajal Gosh [4] in one of his studies examined the relationship between the Indian foreign exchange rate (against US dollar) and crude oil price and found that there exists an inverse relationship between them. Further, the study found that negative and positive oil price shocks did not have a differential impact on the volatility of exchange rate.

The literature documents a good number of research papers that study the nexus between various macro variables against the stock market returns, especially that of developed countries. There are, however, very few studies on the developing or the emerging economies. Adebiyi et al. [5] explored the influence of the fluctuations in the Nigerian stock market and the global crude oil shocks on the Nigerian stock market and found stock markets to be inversely related to the oil price shocks. The study traces the causality to be running from oil prices to the stock market which then gets transmitted to the exchange rate. In the case of Turkey, the exchange rate and the stock market were found to have a bidirectional relationship by Agrawal and Srivastava [6] as well as Aydemir and De- 
mirhan [7]. In an empirical study, Griffin and Stulz's [8] found exchange rate shocks to have a negligible impact on the stock returns.

However, Bartov and Bodnar [2] and Jorion [9] in their studies found the US stock market and the US dollar exchange rate to have no significant relation. For another developed country, Japan, He and $\mathrm{Ng}$ [10] found that only 25 percent of the 171 Japanese multinational companies have had any sort of exposure on their stock returns from the exchange rate fluctuations. In a very interesting study, Chamberlain et al. [11] empirically analyzed the sensitivity of Japanese as well as US bank's stock returns against exchange rate fluctuations. The results showed that while most of the Japanese bank's stock returns remain largely unaffected by exchange rate fluctuations, a greater proportion of the US bank's returns tend to exhibit a positive co-movement with USD fluctuations.

$\mathrm{Ma}$ and Kao [12] found currency appreciation to have a negative impact on the stock markets for export dominant countries while it had a significantly positive impact on import dominant countries. The inter-temporal relationship between stock market returns and the exchange rate was explored by Ajayi and Mougoue [13] for eight economies and found stock returns to exert a positive impact on the domestic currency value over the long run period. Abdalla and Murinde [14], on exploring the causal linkages between stock indices and forex market found the causality to be unidirectional from forex market to stock market.

Though there are several research studies that explore the relationship between stock returns, foreign exchange returns, and oil price returns, most of the studies pertain to be bivariate in nature. In the modern oil dependent globalized economy, it is imperative to study the dynamic interaction and cross volatility spillover between the three markets in a trivariate fashion and our study aims to bridge this gap. Contrary to the common usage of low-frequency monthly data, the study employs a high-frequency daily time series data. Some of the similar studies are available in literature but by large, they pertain to that of the developed countries alone. The study also complements and enhances the existing literature on cross volatility spillovers between macroeconomic variables by comparing the interaction between the underlying variables across five emerging economies.

\section{Data}

The present study employs five-day week, daily time series data on stock returns, forex returns and WTI crude oil returns for five emerging economies. The countries included in the analysis are Brazil, Indonesia, Malaysia, Pakistan, and South Korea. We choose a benchmark stock market index (closing) based on total market capitalization as a proxy for the market performance of a particular county. The data include daily closing prices of 5 representative indexes: Brazil (BOVESPA), Indonesia (JKSE), Malaysia (KLCI), Pakistan (KSE), and South Korea (KOSPI). Further, foreign exchange rates for five emerging economies are also obtained along with the benchmark oil market index i.e. West Texas Inter- 
mediate crude oil rates (WTI), all designated in dollar terms. Table 1 describes the data used in the study.

The data is collected for a period of five years from January 012010 through January 01 2015. The data for the oil price (WTI) is obtained from the database of International Financial Statistics (International Monetary Fund). The exchange rate refers to the number of units of local currency per one USD. The data for the exchange rate are compiled from the OANDA pages. The stock market index data of respective exchanges are obtained from yahoo finance website.

\section{Methodology}

\subsection{Stationary Test (Unit Root Test)}

The data used is a financial time series data which has the inherent problem of being non-stationary in its level form leading to spurious regression if not made stationary. Hence, the daily return of all series was computed as logarithmic differences of successive observations viz. $\mathrm{Rt}=(\ln \mathrm{Pt}-\ln \mathrm{Pt}-1) \times 100$. Then we conducted stationarity tests using ADF (Augmented Dickey-Fuller test) and Phillip Perron (PP) unit root tests to examine the time series properties of the model variables. With that, the data was found to satisfy the condition of stationarity.

\subsection{Modeling Volatility through Trivariate Diagonal BEKK GARCH Model}

The Diagonal BEKK GARCH model is employed in order to assess the volatility

Table 1. Description of Data.

\begin{tabular}{ccc}
\hline Name of the variable & Symbol & Proxy used \\
\hline Crude Oil Prices & WTI & West Texas Intermediate crude oil rates \\
United States Dollar & USD & \\
Brazilian Real & BRL & \\
Indonesian Rupiah & IDR & \\
Malaysian Rupee & MYR & \\
Pakistan Rupee & PKR & \\
South Korean Won & KRW & \\
Brazil Stock Market & BOVESPA & Bolsa de Valores do Estado de São Paulo \\
Indonesia Stock Market & JKSE & Jakarta Stock Exchange \\
Malaysia Stock Market & KLCI & Kuala Lumpur Composite Index \\
Pakistan Stock Market & KSE & Karachi Stock Exchange \\
South Korea Stock Market & KOSPI & Korea Stock Exchange Composite Index \\
\hline
\end{tabular}

(Table 1 indicates the symbol and proxy used for the stock market indices and foreign exchange rates for each of the five countries along with that of the international WTI crude oil price. In the remaining text, the symbols mentioned above will be used instead of variable names for convenience.) 
contagion effects between the three underlying markets for each of the five economies. Diagonal BEKK is a multivariate GARCH model that allows for the explicit and dynamic parameterization of conditional covariances (Engle and Kroner, 1995). By restricting the parameter matrices to be diagonal, the model significantly reduces the number of parameters estimated and by ensuring that the conditional covariance matrix is always positive definite, it also effectively overcomes the difficulty with the alternative VECH model. The general Diagonal BEKK Equation is given as:

$$
H_{t}=\Omega^{\prime} \Omega+A^{\prime}\left(u_{t-1} u_{t-1}^{\prime}\right) A+B^{\prime} H_{t-1} B
$$

where, $H_{t}$ is an $N \times N$ conditional variance-covariance matrix, $\Omega$ is an upper triangular matrix of parameters, $u_{t-1}$ is an $N \times 1$ disturbance vector, and, $A$ and $B$ are $N \times N$ diagonal parameter matrices. A trivariate Diagonal BEKK model can be described as follows.

The $\Omega^{\prime} \Omega$ matrix $(3 \times 3)$ equals:

$$
\begin{aligned}
\Omega^{\prime} \Omega & =\left[\begin{array}{ccc}
\omega_{11} & 0 & 0 \\
\omega_{12} & \omega_{22} & 0 \\
\omega_{13} & \omega_{23} & \Omega \omega_{33}
\end{array}\right]\left[\begin{array}{ccc}
\omega_{11} & \omega_{12} & \omega_{13} \\
0 & \omega_{22} & \omega_{23} \\
0 & 0 & \omega_{33}
\end{array}\right] \\
& =\left[\begin{array}{ccc}
\omega_{11}^{2} & \omega_{11} \omega_{12} & \omega_{11} \omega_{13} \\
\omega_{11} \omega_{12} & \omega_{12}^{2} \omega_{22}^{2} & \omega_{12} \omega_{13}+\omega_{22} \omega_{23} \\
\omega_{11} \omega_{13} & \omega_{12} \omega_{13}+\omega_{22} \omega_{23} & \omega_{13}^{2} \omega_{23}^{2} \omega_{33}
\end{array}\right]
\end{aligned}
$$

The $H_{t}$ matrix can be represented as:

$$
H_{t}=\left[\begin{array}{lll}
h_{11, t} & h_{12, t} & h_{13, t} \\
h_{21, t} & h_{22, t} & h_{23, t} \\
h_{31, t} & h_{32, t} & h_{33, t}
\end{array}\right]
$$

Now, the BEKK Garch equation can be represented as:

$$
\begin{aligned}
& {\left[\begin{array}{lll}
h_{11, t} & h_{12, t} & h_{13, t} \\
h_{21, t} & h_{22, t} & h_{23, t} \\
h_{31, t} & h_{32, t} & h_{33, t}
\end{array}\right]=\left[\begin{array}{ccc}
\omega_{11}^{2} & \omega_{11} \omega_{12} & \omega_{11} \omega_{13} \\
\omega_{11} \omega_{12} & \omega_{12}^{2} \omega_{22}^{2} & \omega_{12} \omega_{13}+\omega_{22} \omega_{23} \\
\omega_{11} \omega_{13} & \omega_{12} \omega_{13}+\omega_{22} \omega_{23} & \omega_{13}^{2} \omega_{23}^{2} \omega_{33}
\end{array}\right]} \\
& +\left[\begin{array}{ccc}
\alpha_{11} & 0 & 0 \\
0 & \alpha_{22} & 0 \\
0 & 0 & \alpha_{33}
\end{array}\right]\left[\left[\begin{array}{l}
u_{1, t-1} \\
u_{2, t-1} \\
u_{3, t-1}
\end{array}\right]\left[\begin{array}{l}
u_{1, t-1} \\
u_{2, t-1} \\
u_{3, t-1}
\end{array}\right]\left[\begin{array}{ccc}
\alpha_{11} & 0 & 0 \\
0 & \alpha_{22} & 0 \\
0 & 0 & \alpha_{33}
\end{array}\right]\right. \\
& +\left[\begin{array}{ccc}
\beta_{11} & 0 & 0 \\
0 & \beta_{22} & 0 \\
0 & 0 & \beta_{33}
\end{array}\right]\left[\begin{array}{lll}
h_{11, t-1} & h_{12, t-1} & h_{13, t-1} \\
h_{21, t-1} & h_{22, t-1} & h_{23, t-1} \\
h_{31, t-1} & h_{32, t-1} & h_{33, t-1}
\end{array}\right]\left[\begin{array}{ccc}
\beta_{11} & 0 & 0 \\
0 & \beta_{22} & 0 \\
0 & 0 & \beta_{33}
\end{array}\right]
\end{aligned}
$$

Thus, each conditional and covariance equation can be represented as:

$$
\begin{gathered}
h_{11, t}=\omega_{11}^{2}+\alpha_{11}^{2} u_{1, t-1}^{2}+\beta_{11}^{2} h_{11, t-1} \\
h_{12, t}=\omega_{11} \omega_{12}+\alpha_{11} \alpha_{22} u_{1, t-1} u_{2, t-1}+\beta_{11} \beta_{22} h_{12, t-1} \\
h_{13, t}=\omega_{11} \omega_{13}+\alpha_{11} \alpha_{33} u_{1, t-1} u_{3, t-1}+\beta_{11} \beta_{33} h_{13, t-1}
\end{gathered}
$$




$$
\begin{gathered}
h_{22, t}=\omega_{12}^{2} \omega_{22}^{2}+\alpha_{22}^{2} u_{2, t-1}^{2}+\beta_{22}^{2} h_{22, t-1} \\
h_{23, t}=\omega_{12} \omega_{13}+\omega_{22} \omega_{23}+\alpha_{22} \alpha_{33} u_{2, t-1} u_{3, t-1}+\beta_{22} \beta_{33} h_{23, t-1} \\
h_{33, t}=\omega_{13}^{2} \omega_{23}^{2} \omega_{33}+\alpha_{33}^{2} u_{3, t-1}^{2}+\beta_{33}^{2} h_{33, t-1}
\end{gathered}
$$

Under the assumption of conditional normality, the parameters of the multivariate GARCH models of any of the above specifications can be estimated by maximizing the log-likelihood function:

$$
\begin{gathered}
r_{t}=\mu+\varepsilon_{t} \text { where } \varepsilon_{t} \sim N\left(0, H_{t}\right) \\
L=-\frac{1}{2} \sum_{t=1}^{T}\left(\log \left|H_{t}\right|+\varepsilon_{t}^{\prime} H_{t}^{-1} \varepsilon_{t}\right)
\end{gathered}
$$

Our study employs a Trivariate Diagonal BEKK Specification. The conditional mean and variance/covariance are estimated simultaneously with a system of three equations.

\section{Empirical Analysis}

\subsection{Descriptive Statistics}

From Table 2, it is clear that the returns on stock indices of all the countries are negatively skewed. The statistic for skewness of lesser than zero implies a left-skewed distribution where most values are concentrated on the right of the mean, with extreme values to the left. From Table 3 we can observe that the foreign exchange returns of Indonesia $(-0.634)$, Malaysia $(-0.111)$, and Pakistan $(-0.37)$, as well as the WTI $(-0.471)$, are also negatively skewed while the foreign exchange returns of Brazil (0.037) and Korea (1.465) exhibit positive skewness.

As can be observed in Table 2, all stock returns indicate excess kurtosis, ranging from the lowest 4.869 (Brazil) to the highest 10.907 (Indonesia) indicating a leptokurtic curve which is sharper than a normal distribution, with the values concentrated around the mean and having thicker tails. This means high

Table 2. Descriptive statistics of stock returns.

\begin{tabular}{cccccc}
\hline Coefficient/SR & Brazil & Indonesia & Malaysia & Pakistan & S Korea \\
\hline Mean & -0.038 & 0.078 & 0.036 & 0.135 & 0.014 \\
Median & -0.049 & 0.163 & 0.065 & 0.121 & 0.020 \\
Maximum & 5.199 & 6.783 & 3.322 & 5.212 & 4.900 \\
Minimum & -8.431 & -9.300 & -4.326 & -5.038 & -6.420 \\
Std. Dev. & 1.612 & 1.400 & 0.691 & 1.086 & 1.207 \\
Skewness & -0.198 & -1.051 & -0.485 & -0.025 & -0.384 \\
Kurtosis & 4.869 & 10.907 & 7.575 & 5.824 & 5.919 \\
Jarque-Bera & 133.26 & 2443.43 & 798.25 & 291.17 & 332.59 \\
Probability & 0.000 & 0.000 & 0.000 & 0.000 & 0.000 \\
Observation & 1284 & 1284 & 1284 & 1284 & 1284 \\
\hline
\end{tabular}


Table 3. Descriptive statistics for forex as well as WTI crude returns.

\begin{tabular}{ccccccc}
\hline Coefficient/FX & Brazil & Indonesia & Malaysia & Pakistan & S Korea & WTI \\
\hline Mean & 0.051 & 0.034 & 0.004 & 0.020 & -0.002 & -0.048 \\
Median & 0.050 & 0.047 & 0.010 & 0.021 & -0.031 & 0.014 \\
Maximum & 3.754 & 2.761 & 3.406 & 1.647 & 6.990 & 9.001 \\
Minimum & -4.695 & -4.086 & -3.410 & -1.96 & -4.240 & -11.60 \\
Std. Dev. & 0.843 & 0.547 & 0.501 & 0.367 & 0.639 & 1.972 \\
Skewness & 0.037 & -0.634 & -0.111 & -0.37 & 1.465 & -0.471 \\
Kurtosis & 6.642 & 12.390 & 9.842 & 6.176 & 22.797 & 7.088 \\
Jarque-Bera & 484.302 & 3276.845 & 1710 & 388 & 14618 & 642.490 \\
Probability & 0.000 & 0.000 & 0.000 & 0.000 & 0.000 & 0.000 \\
Observations & 1284 & 1284 & 1284 & 1284 & 1284 & 1284 \\
\hline
\end{tabular}

probability for extreme values. Table 3 also exhibits a similar trend where the foreign exchange returns are observed to have a much higher kurtosis value than that of the stock returns for all the countries. South Korea has a kurtosis value as high as 22.797 .

Jarque-Bera statistic tests the null hypothesis that data follow a normal distribution. By using probability values of Jarque-Bera statistics, the null hypothesis is rejected for all variables at $1 \%$ level of significance. This shows the non-normal distribution of the exchange rate returns, stock returns as well as WTI returns indicating randomness and inefficiency of the market

\subsection{Stationary Test (ADF Unit Root Test)}

In this study, the Augmented Dickey-Fuller (ADF) and Phillip Perron (PP) unit root tests were employed to test for the time series properties of model variables. The null hypothesis is that the variable under investigation has a unit root against the alternative that it does not. The choice of lag length was based on Akaike and Schwartz-Bayesian information criteria. The decision rule is to reject the null hypothesis if the ADF and PP statistic value exceeds the critical value at a chosen level of significance. The ADF unit root test is performed with all three specifications namely, with intercept, with intercept and trend and none. Results of the model with intercept are presented in Table 4.

The results of Table 4 show that all the variables are non-stationary in level form since their $\mathrm{ADF}$ in absolute values are less than the critical values at 1\%,5\% and $10 \%$, the null hypothesis of unit root was accepted for all the variables but was rejected for the return series. Thus, suggesting that the variables under investigation are integrated of order one. As expected, results of the ADF test (with intercept and trend; none) shows unit root in all indices and stationarity in all return series. Level series have unit root even after correcting for drift and trend. All return series are stationary and possess no trend. 
Table 4. Results of Augmented Dickey-Fuller Unit Root Test (t-stat and P-values).

\begin{tabular}{ccccc}
\hline & \multicolumn{2}{c}{ Stock returns } & \multicolumn{2}{c}{ Exchange rates } \\
\hline \multirow{2}{*}{ Brazil } & At Level & Ln Returns & At Level & Ln Returns \\
& -2.207 & $-29.838^{\star}$ & 0.646 & $-26.798^{\star}$ \\
& $(0.204)$ & $(0.000)$ & $(0.990)$ & $(0.000)$ \\
Indonesia & -1.522 & $-19.802^{\star}$ & 0.786 & $-30.286^{\star}$ \\
& $(0.522)$ & $(0.000)$ & $(0.993)$ & $(0.000)$ \\
Malaysia & -1.633 & $-26.315^{\star}$ & -1.429 & $-28.353^{\star}$ \\
& $(0.465)$ & $(0.000)$ & $(0.569)$ & $(0.000)$ \\
Pakistan & 1.251 & $-27.105^{\star}$ & -0.781 & $-33.452^{\star}$ \\
& $(0.998)$ & $(0.000)$ & $(0.823)$ & $(0.000)$ \\
S Korea & 0.134 & $-28.475^{*}$ & -2.288 & $-21.97^{\star}$ \\
& $(0.968)$ & $(0.000)$ & $(0.176)$ & $(0.000)$ \\
WTI & At Level & -1.232 & Ln Returns & $-19.182^{\star}$ \\
& & $(0.662)$ & & $(0.000)$ \\
\hline
\end{tabular}

(Figures in parenthesis are the probabilities of being significant. ${ }^{*}$ represent significant at $1 \%$ level. For constant model, critical value at $1 \%$, level of significance is -3.4379 )

\subsection{Cross-Correlation between Variables}

Table 5 indicates that WTI is negatively correlated with all the foreign currencies except for PKR. As expected, WTI shows a positive correlation with all of the stock returns. A positive correlation among the foreign exchange returns for all the nations is observed. Significant cross-correlations are also evident between the stock returns and their respective foreign exchange returns. Consistent with the economic theories, we can also see that there is a negative correlation between the foreign exchange returns and the stock returns. This is because the growth of the stock market is indicated by a rise in indices while the strengthening (rise in value) of a domestic currency is indicated by a reduction in the exchange rate in nominal terms against other currencies (dollar). An exception to this is the positive correlation for BOVESPA and KLCI against PKR. Judging by the size of the coefficients, there is a highly significant positive correlation (0.658) between MYR and KRW. KRW also has a significant positive correlation with BRL (0.371) as well as IDR (0.333). In tune with the above observations, MYR also has a significant positive correlation with BRL (0.489) and IDR (0.383). From the table, we can also infer that there is a significant negative correlation $(-0.309)$ between KLCI and the BRL. Correlation is least between PKR and KOSPI.

\subsection{Volatility Clustering}

The market returns are influenced by multiple factors such as shocks and turbulence in markets, forces of demand and supply, socio-economic and political state of the country etc. The natural outcome of this is the randomness in returns. Such randomness in returns is called as volatility or returns with 
Table 5. Correlation Coefficients of WTI with Foreign Exchange Returns and Stock Returns.

\begin{tabular}{|c|c|c|c|c|c|c|c|c|c|c|c|}
\hline & $W T I$ & $B R L$ & $I D R$ & $M Y R$ & $P K R$ & $K R W$ & BOVESPA & $J K S E$ & $K L C I$ & $K S E$ & KOSPI \\
\hline$W T I$ & 1 & -0.075 & -0.049 & -0.039 & 0.031 & -0.001 & 0.067 & 0.152 & 0.138 & 0.007 & 0.202 \\
\hline$B R L$ & & 1 & 0.22 & 0.489 & 0.071 & 0.371 & -0.261 & -0.236 & -0.309 & -0.113 & -0.283 \\
\hline$I D R$ & & & 1 & 0.383 & 0.059 & 0.333 & -0.159 & -0.135 & -0.165 & $5-0.029$ & -0.09 \\
\hline$M Y R$ & & & & 1 & 0.016 & 0.658 & -0.282 & -0.171 & -0.277 & -0.098 & -0.205 \\
\hline$P K R$ & & & & & 1 & 0.032 & 0.033 & -0.07 & 0.022 & -0.026 & 0.002 \\
\hline$K R W$ & & & & & & 1 & -0.281 & -0.188 & -0.299 & -0.123 & -0.24 \\
\hline BOVESPA & & & & & & & 1 & 0.347 & 0.365 & 0.144 & 0.428 \\
\hline$J K S E$ & & & & & & & & 1 & 0.517 & 0.19 & 0.521 \\
\hline$K L C I$ & & & & & & & & & 1 & 0.213 & 0.495 \\
\hline$K S E$ & & & & & & & & & & 1 & 0.193 \\
\hline$K O S P I$ & & & & & & & & & & & 1 \\
\hline
\end{tabular}

heteroscedastic variance. Now, the volatility may persist over a period of time (i.e. a period of high returns are followed by subsequent periods of higher returns and a period of low returns are followed by subsequent periods of lower returns), resulting in volatility clustering and may spread across various financial markets resulting in what is called as volatility spillover. Indeed, if the clusters of volatility are removed from the data, the returns would be approximately log-normal.

The plots of market volatility can act like an electrocardiogram, reflecting the pulse of the underlying markets. Figure A1 in appendix shows the daily return series of international crude oil prices. It is very clear from the figure that the size of variation is occasionally higher compared to its normal trend. Among the three variables under study, WTI returns exhibit the largest variance with periods of high volatility and periods of low volatility occurring at random intervals. Figures A2-A6 in appendix display the combination graph of returns in WTI, stock index and foreign exchange rate. It is observed that the foreign exchange returns are generally less volatile with MYR having the least variance. Relatively, among the five countries, BRL has the highest variance followed by KRW. Unlike the foreign exchange returns, the stock exchange returns exhibit higher variances as well as higher volatility clustering. Stock returns volatility is the highest for KOSPI followed by JKSE and BOVESPA. However, the stock returns of KLCI exhibit high stability with the lowest variance among other stock market indices. It can thus be inferred that the Malaysian stock market, as well as its currency, is not largely affected by the fluctuations in international crude oil prices.

Figures A1-A6 show evidence of volatility clustering in returns across all stock markets and international crude oil market. In financial literature, this phenome- 
non is called 'time-varying conditional volatility'. The stylized facts of volatility clustering mean that stock market risk and WTI crude oil price risk are not constant over time (at least as measured by volatility) and while their prices, except for a long-term upward trend are not predictable, their volatility is somewhat predictable. It is also observed that when volatility clusters, stock returns are typically, but not always, low or negative (the largest of the extreme negative moves are usually larger on average than the largest extreme positive moves). This is probably because the news events that affect stock market prices are more often bad news rather than good news. Such kind of an inference cannot be made in the case of crude oil returns as large extreme positives moves as well as large extreme negative moves occur simultaneously at almost equal intervals.

Further, just by looking at the Figures A2-A6, we can observe that a positive shock in stock market volatility is preceded by a higher positive shock in WTI returns and a negative shock in stock market volatility is preceded by a higher negative shock in WTI returns. Hence, we can roughly interpret that huge fluctuations/shocks in WTI returns exert considerable influence over the stock markets of all the countries resulting in stock markets responding to such WTI shocks in a similar trend with a small time lag.

\subsection{Trivariate BEKK GARCH Model with Diagonal Restriction}

As observed in Figures A1-A6, the returns data exhibit volatility clustering, validating the presence of conditional heteroscedasticity in the data. Thus we can introduce Autoregressive Conditional Heteroscedasticity (ARCH) or Generalized Autoregressive Conditional Heteroscedasticity (GARCH) class of models to match and analyze the data series. Here, a trivariate Diagonal BEKK GARCH model is used to estimate the time-varying conditional variance and to test the own-volatility spillover effects of returns of the stock index, the West Texas Intermediate crude oil prices and the bilateral exchange rate between the US dollar and the local currency of each country.

The estimation of a multivariate GARCH model involves the joint estimation of both mean and variance equations. We specify the Diagonal BEKK GARCH model used in the study as stated below:

Mean Equation:

$$
y=m u+l a m b d a * H+r e s
$$

Variance Equation:

$$
\begin{gathered}
H=\text { omega } a^{\prime} \text { omega }+ \text { alpha' } * \text { res }(-1) * \text { res }(-1)^{\prime} * \text { alpha }+ \text { beta } * H(-1) * \text { beta } \\
\text { Series } y 1=\text { Stock Returns } \\
\text { Series } 2=\text { WTI Returns } \\
\text { Series } 1=\text { Forex Returns }
\end{gathered}
$$

The mean equation results are presented in Table 6. Lambda values are found to be significant at $1 \%$ level of significance for Jakarta Stock Exchange while it is found to be significant at $5 \%$ level for the Indonesian Rupiah. Thus the mean 
Table 6. Country-wise Lambda Coefficients of Stock, WTI and Forex Returns.

\begin{tabular}{lccccc}
\hline & Brazil & Indonesia & Malaysia & Pakistan & S Korea \\
\hline Stock Returns & 0.118496 & 0.038691 & 0.140773 & 0.099914 & 0.006898 \\
& $(0.2167)$ & $(0.0006)^{*}$ & $(0.0564)$ & $(0.4895)$ & $(0.8321)$ \\
WTI Returns & 0.039813 & 0.050932 & 0.166028 & 0.121527 & 0.103896 \\
& $(0.387)$ & $(0.1717)$ & $(0.3074)$ & $(0.2933)$ & $(0.8946)$ \\
Forex Returns & 0.020874 & 0.161458 & -0.03463 & 1.382328 & 0.078812 \\
& $(0.7881)$ & $(0.0339)^{* *}$ & $(0.8967)$ & $(0.0921)$ & $(0.568)$ \\
\hline
\end{tabular}

(Figures in parenthesis are the probabilities of being significant. ${ }^{*}$ and ${ }^{* *}$ represent significance at $1 \%$ level and $5 \%$ respectively.)

value of returns for JKSE and IDR is found to be influenced by their own past volatilities. In all the other cases, the volatility fluctuations in the markets do not exert a significant impact on their respective mean returns. That is to say, mean spillover is found not to exist in all financial markets except for the Jakarta Stock Exchange and the Indonesian Rupiah. However, as regards to volatility spillovers, it was observed that the lagged variance of the variables (GARCH effect) as well as their lagged squared residuals from the mean equation (ARCH effect) has a positive and significant impact on the current volatility.

The conditional variance-covariance equations as stated by the Diagonal BEKK specification are as follows.

$$
\begin{gathered}
h_{11, t}=\omega_{11}^{2}+\alpha_{11}^{2} u_{1, t-1}^{2}+\beta_{11}^{2} h_{11, t-1} \\
h_{12, t}=\omega_{11} \omega_{12}+\alpha_{11} \alpha_{22} u_{1, t-1} u_{2, t-1}+\beta_{11} \beta_{22} h_{12, t-1} \\
h_{13, t}=\omega_{11} \omega_{13}+\alpha_{11} \alpha_{33} u_{1, t-1} u_{3, t-1}+\beta_{11} \beta_{33} h_{13, t-1} \\
h_{22, t}=\omega_{12}^{2} \omega_{22}^{2}+\alpha_{22}^{2} u_{2, t-1}^{2}+\beta_{22}^{2} h_{22, t-1} \\
h_{23, t}=\omega_{12} \omega_{13}+\omega_{22} \omega_{23}+\alpha_{22} \alpha_{33} u_{2, t-1} u_{3, t-1}+\beta_{22} \beta_{33} h_{23, t-1} \\
h_{33, t}=\omega_{13}^{2} \omega_{23}^{2} \omega_{33}+\alpha_{33}^{2} u_{3, t-1}^{2}+\beta_{33}^{2} h_{33, t-1}
\end{gathered}
$$

Based on the equations above, the ARCH and GARCH coefficients are computed and are consolidated in Table 7 . The equations effectively capture the own-volatility and cross volatility among the three underlying variables, namely, stock returns, WTI oil returns and forex returns for Brazil, Indonesia, Malaysia, Pakistan and South Korea. We find all the alphas (ARCH coefficients) and betas (GARCH coefficients) to be statistically significant at $1 \%$ level of significance.

The results above stands evidence for the presence of strong GARCH effect, while it corroborates the presence of a very weak ARCH effect among the variables. It can be deduced from the equations that there exists a statistically significant co-variation in return volatilities that are dependent more on its lags rather than on past errors. Arch coefficients from Table 7 corroborates that the own-volatility spillovers are positive and significant for all the three underlying markets for all the five countries. However, the observed effect of past 
Table 7. Country-wise ARCH and GARCH Coefficients of Stock, WTI and Forex Returns.

\begin{tabular}{|c|c|c|c|c|c|c|c|}
\hline & & $\mathrm{AR}$ & H Coeffi & & GA & CH Coeff & \\
\hline \multirow{4}{*}{ 节 } & Variables & BOVESPA & WTI & BRL & BOVESPA & WTI & BRL \\
\hline & BOVESPA & 0.0511 & 0.0431 & 0.0668 & 0.8727 & 0.9101 & 0.8764 \\
\hline & WTI & & 0.0426 & 0.0562 & & 0.9374 & 0.9139 \\
\hline & BRL & & & 0.0871 & & & 0.8799 \\
\hline \multirow{4}{*}{ 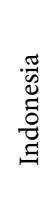 } & Variables & JKSE & WTI & IDR & JKSE & WTI & IDR \\
\hline & JKSE & 0.0974 & 0.0787 & 0.1612 & 0.8838 & 0.9001 & 0.8015 \\
\hline & WTI & & 0.0426 & 0.1302 & & 0.9374 & 0.8162 \\
\hline & IDR & & & 0.2668 & & & 0.7268 \\
\hline \multirow{4}{*}{ 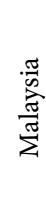 } & Variables & KLCI & WTI & MYR & KLCI & WTI & MYR \\
\hline & KLCI & 0.1459 & 0.0539 & 0.0818 & 0.7393 & 0.8325 & 0.7879 \\
\hline & WTI & & 0.0426 & 0.0302 & & 0.9374 & 0.8873 \\
\hline & MYR & & & 0.0419 & & & 0.8399 \\
\hline \multirow{4}{*}{ 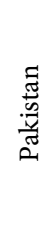 } & Variables & KSE & WTI & PKR & KSE & WTI & PKR \\
\hline & KSE & 0.0726 & 0.0556 & 0.1005 & 0.8007 & 0.8544 & 0.5412 \\
\hline & WTI & & 0.0426 & 0.0769 & & 0.9374 & 0.5775 \\
\hline & PKR & & & 0.1390 & & & 0.3658 \\
\hline \multirow{4}{*}{$\begin{array}{l}\mathscr{J} \\
\tilde{0} \\
\tilde{n} \\
\text { s. }\end{array}$} & Variables & KOSPI & WTI & KRW & KOSPI & WTI & KRW \\
\hline & KOSPI & 0.1049 & 0.0176 & 0.1269 & 0.8504 & 0.9055 & 0.8089 \\
\hline & WTI & & 0.0426 & 0.0213 & & 0.9374 & 0.8614 \\
\hline & KRW & & & 0.1535 & & & 0.7696 \\
\hline
\end{tabular}

(All the alpha and beta coefficients were found to be significant at $1 \%$ level of significance. In the table above, the ARCH and GARCH coefficients were computed using the Diagonal BEKK GARCH specifications).

innovations on the current volatility is very small in all the cases. It is interesting to note that among the three underlying markets, the forex returns tend to have the maximum own-volatility spillover effect, followed by the stock returns and the WTI crude returns for all the countries under study except for Malaysia, where KLCI has a larger own volatility spillover while MYR has the least. These coefficients show the volatility persistence for each market in terms of its own past errors.

As for cross-volatility ARCH effects, consistent with the previous observations, the past innovations in the forex returns exert the greatest influence on the current volatility of stock returns followed by that of the WTI. Therefore, the above results suggest that the past innovations in the forex returns have a positive and significant impact on the future volatility in case of their respective stock returns.

Now, the GARCH effect tends to be a very strong factor in determining the 
future volatilities of all the three variables. As is highly intuitive, WTI returns tend to exhibit extremely high own-volatility GARCH effect with 94 percent of the future variance being determined by the past variance. In other words, WTI exhibits a huge dependence of current volatility on their own one period lagged volatility. Hence, WTI volatility is by and large highly predictable just by looking at the one time period lagged variance. Except for KLCI with 73 percent own-volatility GARCH effect, all the other stock markets show strong evidence of variance spillovers within a range of 80 to 87 percent. However, the own-volatility GARCH effects for forex returns show mixed results with spillovers as high as 88 percent in the case of BRL to as low as 37 percent in the case of PKR.

The cross volatility GARCH effect is highest between WTI and stock markets for all the economies except Malaysia where the highest influence on KLCI is exerted by the MYR. The observations state a strong causal relationship between oil price fluctuations and stock returns. The above observations show that any fluctuations in the international crude prices will soon get reflected in the domestic stock prices for all the countries with an immediate and strong lag effect. The cross volatility GARCH effect is the weakest for the KLCI as the Malaysian stock market is still in its growth phase. It is also interesting to observe that PKR is not affected largely by fluctuations in both KSE and WTI. This is mostly because of the high volatile nature of the PKR along with a less competent stock market and little dependence on oil imports by volume.

Therefore the volatility of each variable does not affect the mean value of their respective returns. However, the lagged variance of the variables as well as their lagged squared residuals from the mean equation has a positive and significant impact on the current volatility. The results of the conditional variance equations depict the presence of significant conditional heteroscedasticity in the return series of stock market and forex market of all five countries. The same holds for the WTI crude oil market as well. Significant own volatility spillover exists in the WTI returns followed by stock returns and forex returns. Past returns in variables have a greater effect on current returns, validating the time-varying co-movement of returns as a leading forecasting factor.

\section{Conclusions}

It is of paramount importance to understand the impact of oil price shocks on financial and foreign exchange markets particularly in the case of emerging economies as they are expected to exert a larger influence over the global economy over the coming years. As a result of globalization and liberalization of capital markets, the investors are anticipated to diversify their portfolios across international currencies and national stock markets. Since exchange rate risk and its relationship with the domestic stock market is an important determinant of the overall portfolio risk, this trend is expected to link the forex market and stock market more closely. Such linkages manifest themselves in the form of cross volatility spillovers, over and above the mean returns spillover. At this 
juncture, the own and cross volatility spillover analysis would help investors in predicting the market movement to a larger precision irrespective of the impact of other macroeconomic variables on the price behavior of the underlying variable. The evidence presented in this paper does indeed bear out such an expectation.

We find that huge fluctuations in WTI returns exert considerable influence over the stock markets. Further, significant own volatility spillover exists in the WTI returns followed by stock returns and forex returns. Past returns in variables have a greater effect on current returns, validating the time-varying co-movement of returns as a leading forecasting factor. The lagged variance of the variables as well as their lagged squared residuals from the mean equation has a positive and significant impact on the current volatility in most cases.

The findings of the study are of great importance to financiers, economists, investors, and policymakers. A proficient understanding of the volatility spillover among crude oil market, stock market and foreign exchange market returns, and subsequently the degree of their integration, would increase the information set available to multinational corporations, policymakers, and international as well as domestic investors for better decision making. This would also help in the pricing of securities, optimizing portfolios as well as in developing hedging strategies. The study would also complement the existing literature on how the behavior of returns and volatility spillover in one economy compares with those of other emerging economies.

\section{References}

[1] Apte, P.G. (1997) Currency Exposure and Stock Prices. Journal of Foreign Exchange and International Finance, 12, 135-143.

[2] Bartov, E. and Bodnar, G.M. (1994) Firm Valuation, Earnings Expectations, and the Exchange-Rate Exposure Effect. The journal of Finance, 49, 1755-1785. https://doi.org/10.1111/j.1540-6261.1994.tb04780.x

[3] Wang, M.L., Wang, C.P. and Huang, T.Y. (2010) Relationships among Oil Price, Gold Price, Exchange Rate and International Stock Markets. International Research Journal of Finance and Economics, 47, 80-89.

[4] Ghosh, S. (2011) Examining Crude Oil Price-Exchange Rate Nexus for India during the Period of Extreme Oil Price Volatility. Applied Energy, 88, 1886-1889. https://doi.org/10.1016/j.apenergy.2010.10.043

[5] Adebiyi, M.A., Adenuga, A.O., Abeng, M.O. and Omanukwue, P.N. (2009) Oil Price Shocks, Exchange Rate and Stock Market Behaviour: Empirical Evidence from Nigeria. Proceedings of the 14th Annual Conference of the African Econometric Society, Abuja, July 2009.

[6] Agrawal, G. and Srivastava, A. (2011) Stock Market Return and Exchange Rate Volatility: A GARCH Application. Research Journal of International Studies, 20, 12-23.

[7] Aydemir, O. and Demirhan, E. (2009) The Relationship between Stock Prices and Exchange Rates: Evidence from Turkey. International Research Journal of Finance and Economics, 23, 207-215.

[8] Griffin, J.M. and Stulz, R.M. (2001) International Competition and Exchange Rate Shocks: A Cross-Country Industry Analysis of Stock Returns. Review of Financial Studies, 14, 215-241. https://doi.org/10.1093/rfs/14.1.215 
[9] Jorion, P. (1991) The Pricing of Exchange Rate Risk in the Stock Market. Journal of Financial and Quantitative Analysis, 26, 363-376. https://doi.org/10.2307/2331212

[10] He, J. and Ng, L.K. (1998) The Foreign Exchange Exposure of Japanese Multinational Corporations. The Journal of Finance, 53, 733-753.

https://doi.org/10.1111/0022-1082.295575

[11] Chamberlain, S., Howe, J.S. and Popper, H. (1997) The Exchange Rate Exposure of US and Japanese Banking Institutions. Journal of Banking \& Finance, 21, 871-892. https://doi.org/10.1016/S0378-4266(97)00002-2

[12] Ma, C.K. and Kao, G.W. (1990) On Exchange Rate Changes and Stock Price Reactions. Journal of Business Finance \& Accounting, 17, 441-449. https://doi.org/10.1111/j.1468-5957.1990.tb01196.x

[13] Ajayi, R.A. and Mougoue, M. (1996) On the Dynamic Relation between Stock Prices and Exchange Rates. Journal of Financial Research, 19, 193-207. https://doi.org/10.1111/j.1475-6803.1996.tb00593.x

[14] Abdalla, I.S. and Murinde, V. (1997) Exchange Rate and Stock Price Interactions in Emerging Financial Markets: Evidence on India, Korea, Pakistan and the Philippines. Applied Financial Economics, 7, 25-35.

https://doi.org/10.1080/096031097333826 


\section{Appendix}

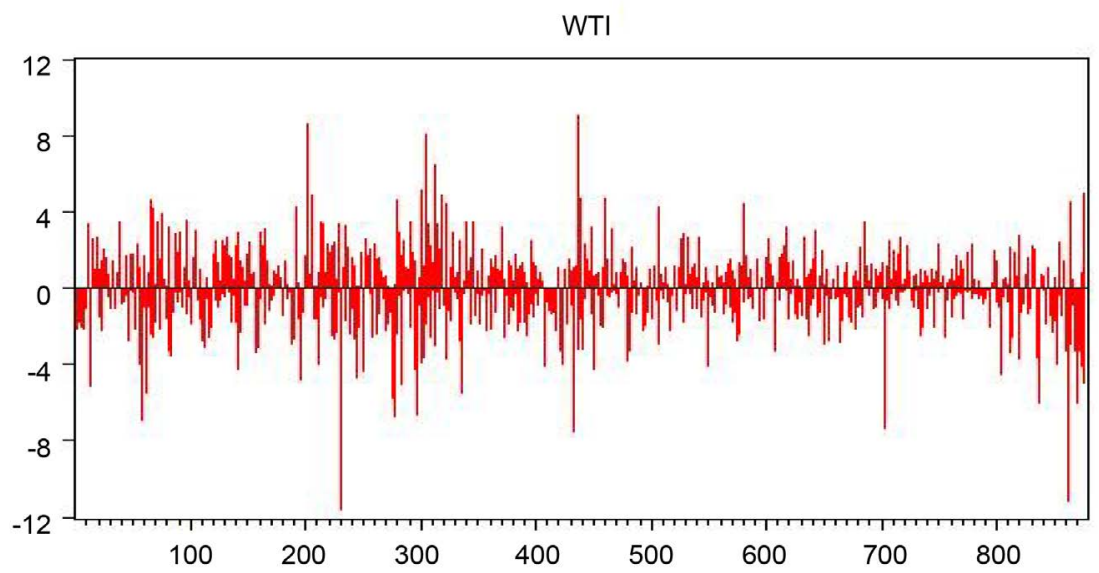

Figure A1. Returns of WTI.

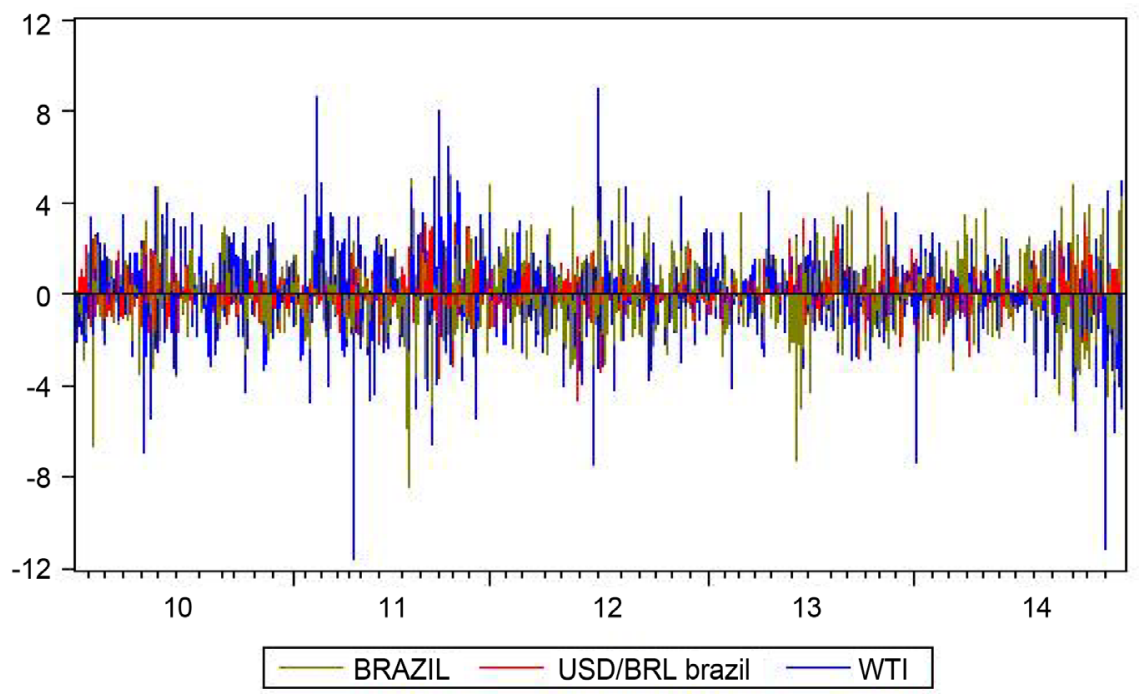

Figure A2. Combination graph of returns in BOVESPA, BRL and WTI.

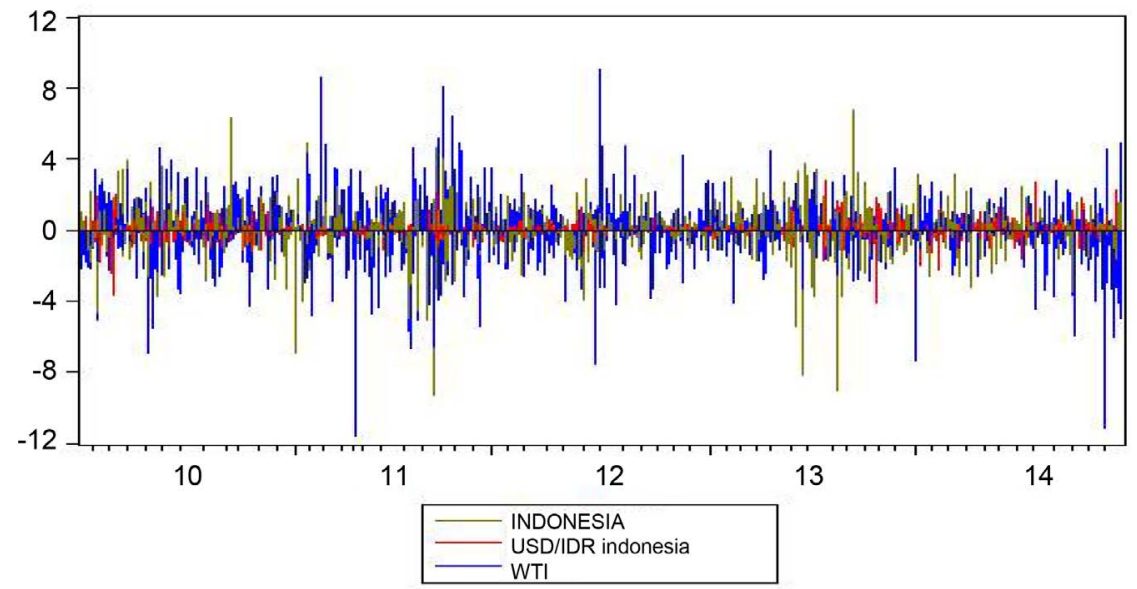

Figure A3. Combination graph of returns in JKSE, IDR and WTI. 


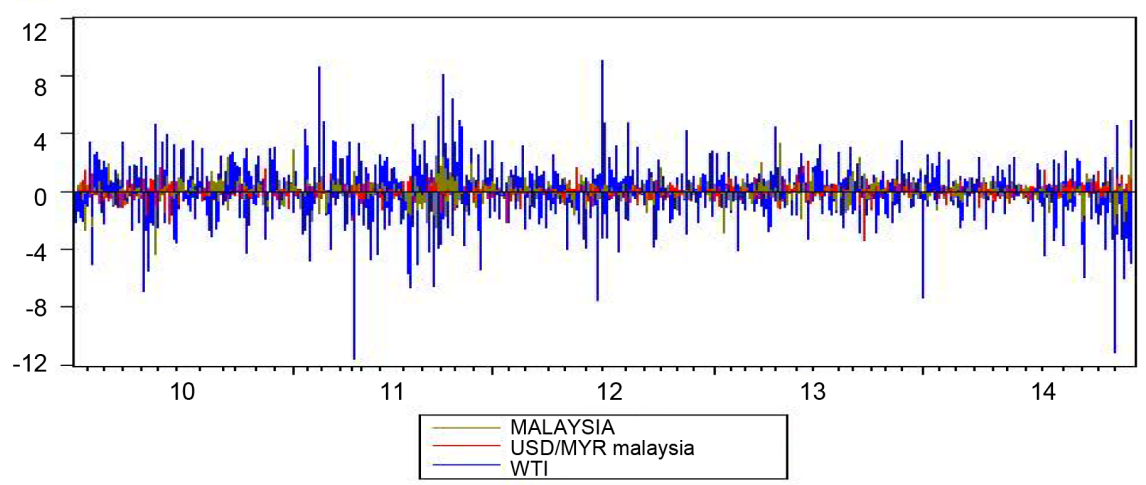

Figure A4. Combination graph of returns in KLCI, MYR and WTI.

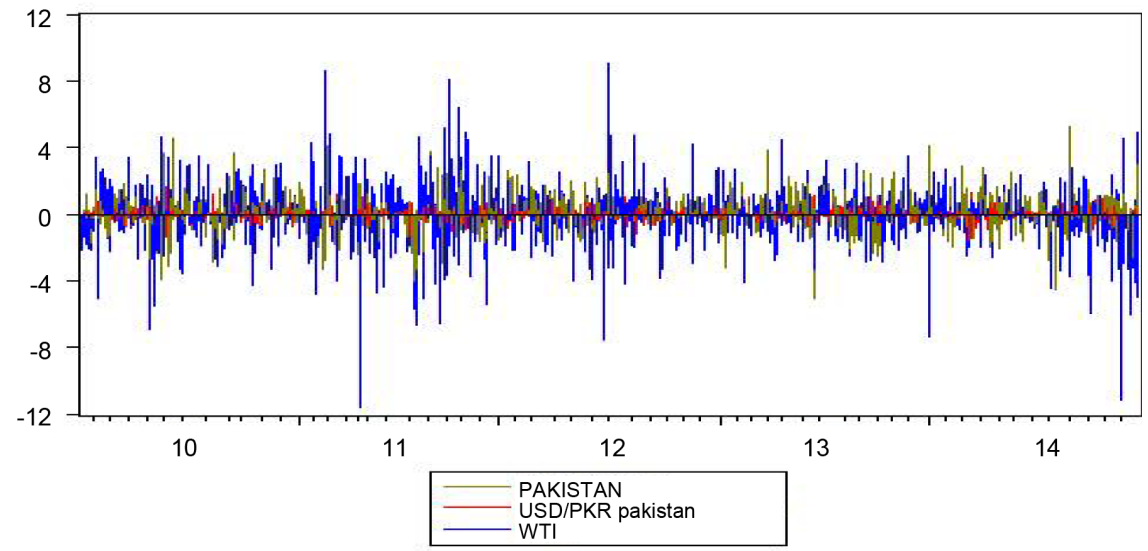

Figure A5. Combination graph of returns in KSE, PKR and WTI.

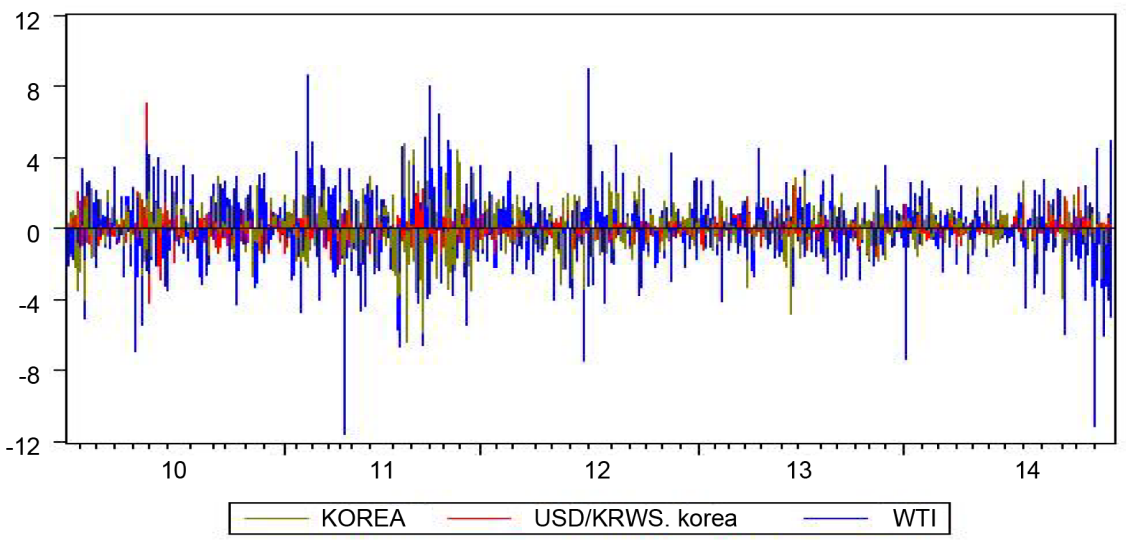

Figure A6. Combination graph of returns in KOSPI, KRW and WTI. 